\title{
BLOOD PRESSURE EFFECTS OF LOWER ABDOMINAL AORTIC SURGERY WITH PARTICULAR REFERENCE TO THE USE OF MORPHINE AND DROPERIDOL IN MODIFYING THE RESPONSES
}

\author{
Anthony S.W. Au, David Evans, Ronald Crago, and William M. Jones
}

DESPITE THE DECREASE IN THE MORTALITY RATE associated with abdominal aortic operations in the last two decades ${ }^{1}$ intra-operative haemodynamic changes still occur very frequently. Sudden and severe hypertension may cause myocardial failure or ischaemia, rupture of an asymptomatic cerebral aneurysm or increased bleeding. Severe hypotension may lead to myocardial infarction, cerebral vascular thrombosis, or renal failure.

Reasons for the hypertensive changes in aortic surgery are scarce in the literature. A common explanation in clinical practice is that mechanical obstruction from cross-clamping of the aorta increases peripheral resistance. However, it has been our observation that despite adequacy of anaesthesia hypertensive responses occur before cross-clamping of the aorta, sometimes to a greater degree than those produced by the actual occlusion, and that droperidol appears to modify these hypertensive changes. The aim of our study was to confirm or refute these two observations.

\section{Method}

Patients between the ages of 40 and 70 years who had been admitted for elective infra-renal aortic operations were selected if they were free from hypertension and severe cardio-pulmonary disease. Hypertension was defined as systolic blood pressure above 150 torr $(20 \mathrm{kPa})$ and diastolic above 100 torr $(13.5 \mathrm{kPa})$. Patients with a history of ingestion of drugs with known effects on catecholamine metabolism were also excluded. The patients were divided into two groups:

Group $M$ (Morphine). Hydration of these patients was maintained with intravenous balanced salt solution for 12 to 15 hours before the operation. Premedication was with intramuscular morphine $0.2 \mathrm{mg} / \mathrm{kg}$ one hour pre-operatively. Intravenous thiopentone was administered for induction and pancuronium was the muscle relaxant chosen. The trachea was intubated and the lungs ventilated to produce a $\mathrm{Pa}_{\mathrm{O}_{2}}$ of $100-150$ torr $\left(13.5-20 \mathrm{kPa}\right.$ ) and $\mathrm{PaCO}_{2}$ of $40 \pm 5$ torr (5.3 \pm $0.7 \mathrm{kPa}$ ). After intubation, morphine $10 \mathrm{mg}$ was administered intravenously every minute to a total dose of $1 \mathrm{mg} / \mathrm{kg}$. Anaesthesia was maintained with nitrous oxide, oxygen, and pancuronium. Heart rate, arterial blood pressure, and central venous pressure (CVP) were taken at specific points during the operation. In addition, blood catecholamine estimations were done in one patient at rest 15 minutes before induction, during the skin incision, during mesenteric traction, and five minutes

The Department of Anaesthesia, Toronto Western Hospital and University of Toronto, Toronto, Ontario, Canada. 
after the aorta had been cross-clamped. Elective post-operative mechanical ventilation was instituted in all patients.

Group D. (Droperidol). Management of the patients in this group was the same as for Group $M$ except that, in addition, droperidol $2.5 \mathrm{mg}$ was administered intravenously every five minutes to a total dose of $0.25 \mathrm{mg} / \mathrm{kg}$ after morphine $1 \mathrm{mg} / \mathrm{kg}$ had been given.

All statistical analyses were by Student's t-test.

\section{RESULTS}

Eight patients were included in the morphine group, and seven patients vere in the droperidol group. All the patients recovered from the operation without complications.

Figures 1, 2 and 3 show the mean systolic and diastolic blood pressures and heart rates, with standard deviations, in the two groups of patients at various stages of

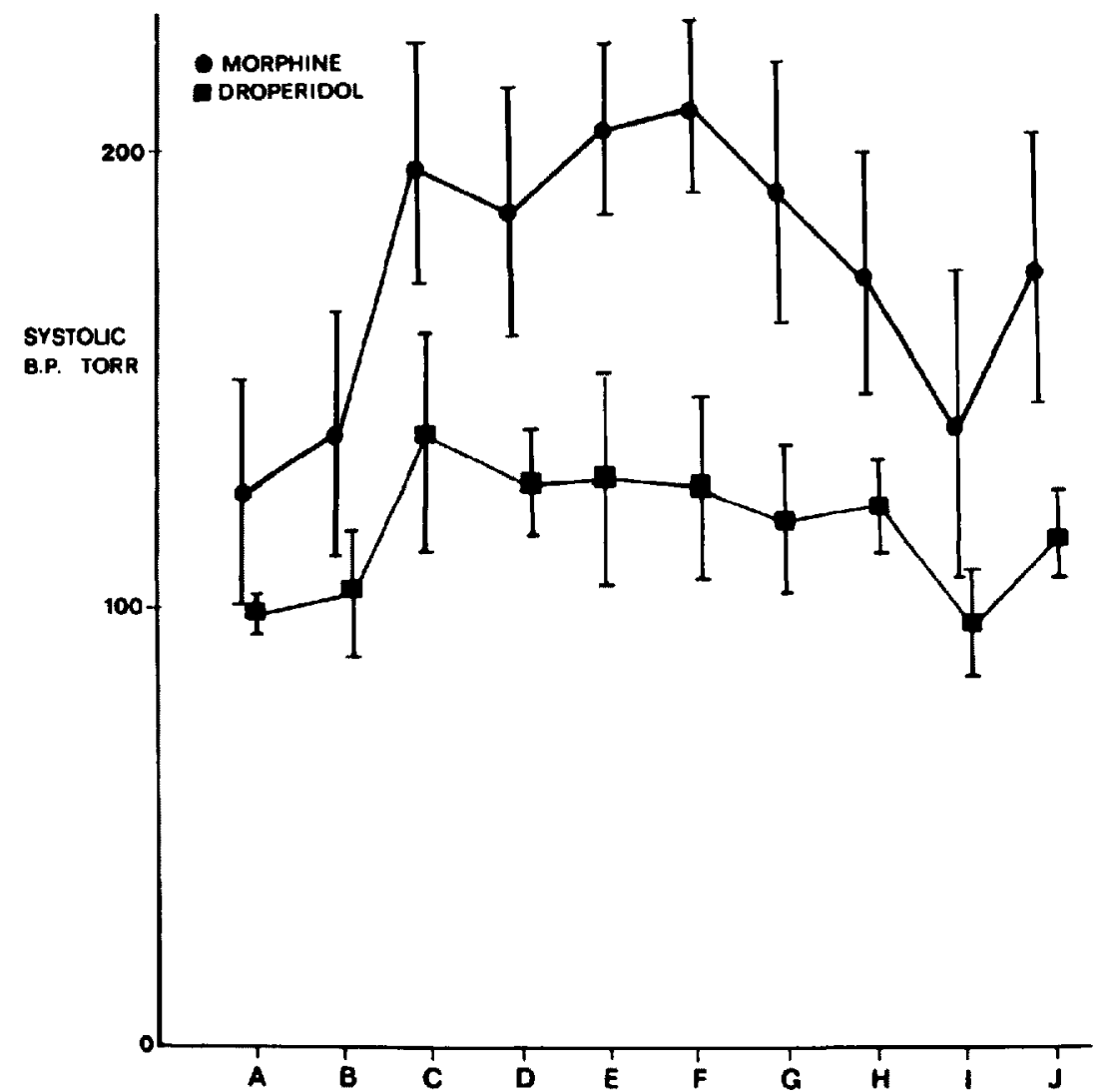

Figure 1. Mean systolic blood pressures and standard deviations in operations on the lower abdominal aorta. A - baseline, B - skin incision, C - mesenteric traction, D - femoral or iliac arterial manipulation, $\mathrm{E}$ - aortic manipulation, $\mathrm{F}$ - cross-clamping of the aorta, $\mathrm{G}$ - five minutes after cross-clamping of the aorta, $\mathrm{H}$ - pre-declamping of the aorta, I - aorta declamped, $\mathrm{J}$ - five minutes after declamping of the aorta. 


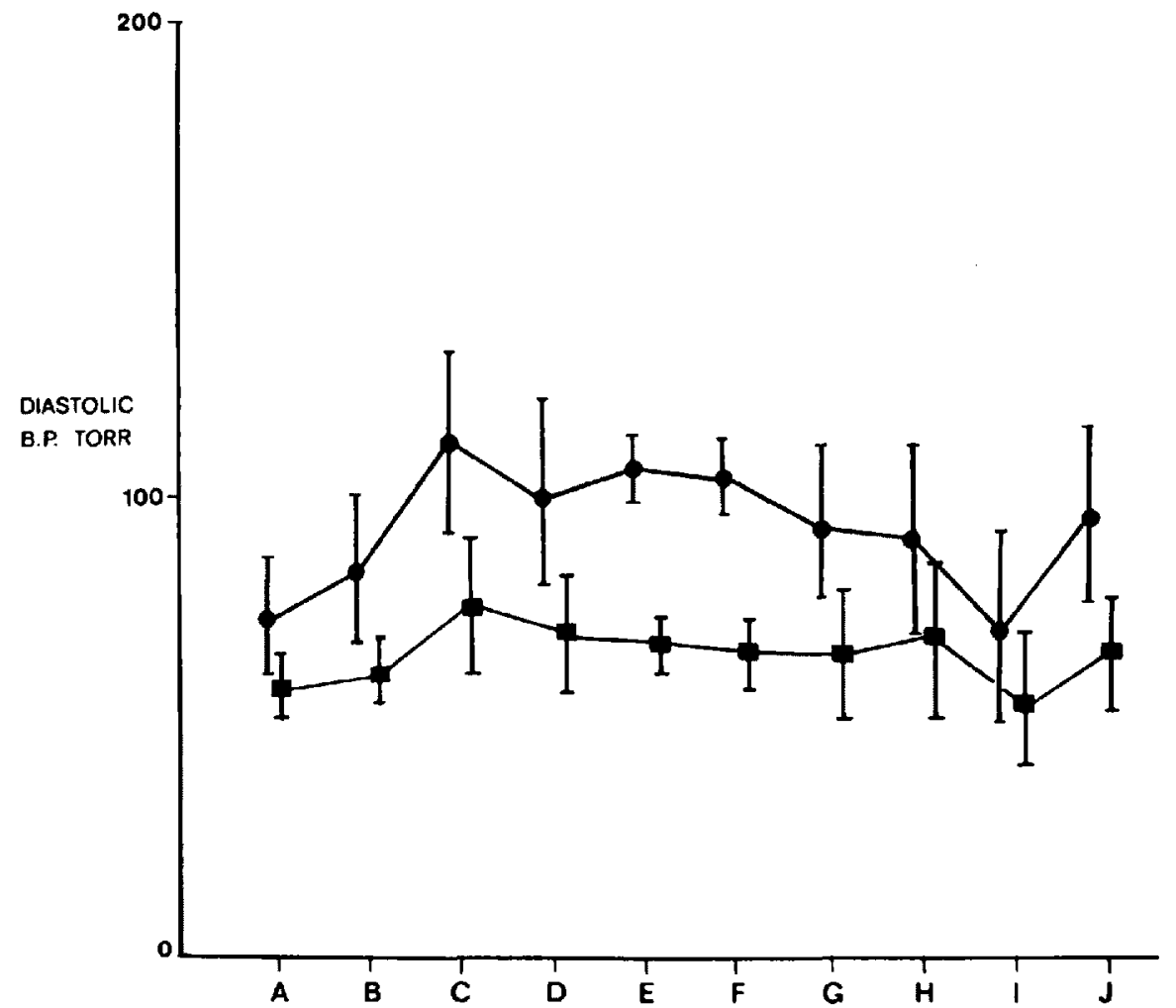

Froune 2. Mean diastolic blood pressures and standard deviations in operations on the lower abdominal aorta. A to J-same as in Figure 1.

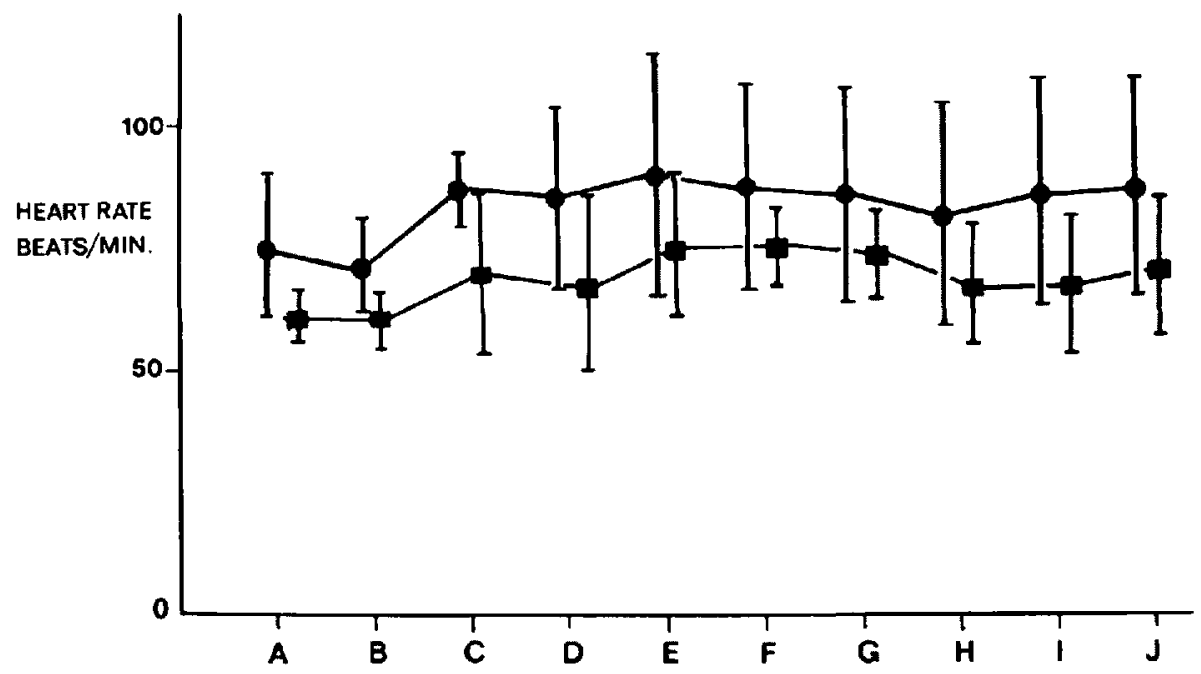

Figure 3. Mean heart rate and standard deviations in operations on the lower abdominal aorta. A to $\mathrm{J}$-same as in Figure 1. 

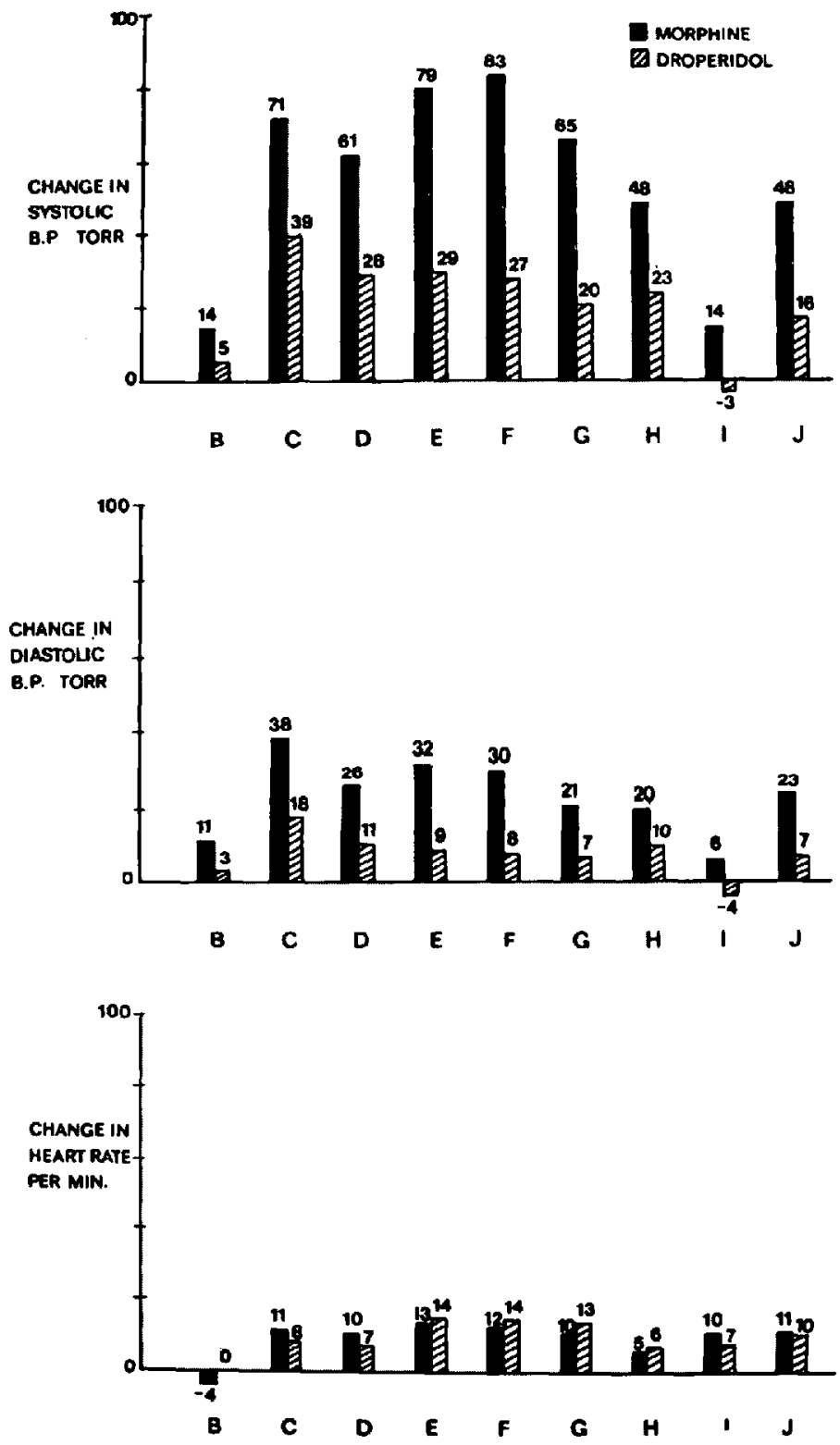

Ficure 4. Changes in systolic and diastolic blood pressures and heart rate from the baselines in operations on the lower abdominal aorta. B to J - same as in Figure 1.

the operation. The baseline values of blood pressure and heart rate are the values after induction of anaesthesia and administration of morphine in Croup $M$, and morphine and droperidol in Group $D$, but before the skin incision.

Comparison of baseline values of blood pressure and heart rate with the values at various stages of the operation in both groups is shown in Figure 4. Significant 


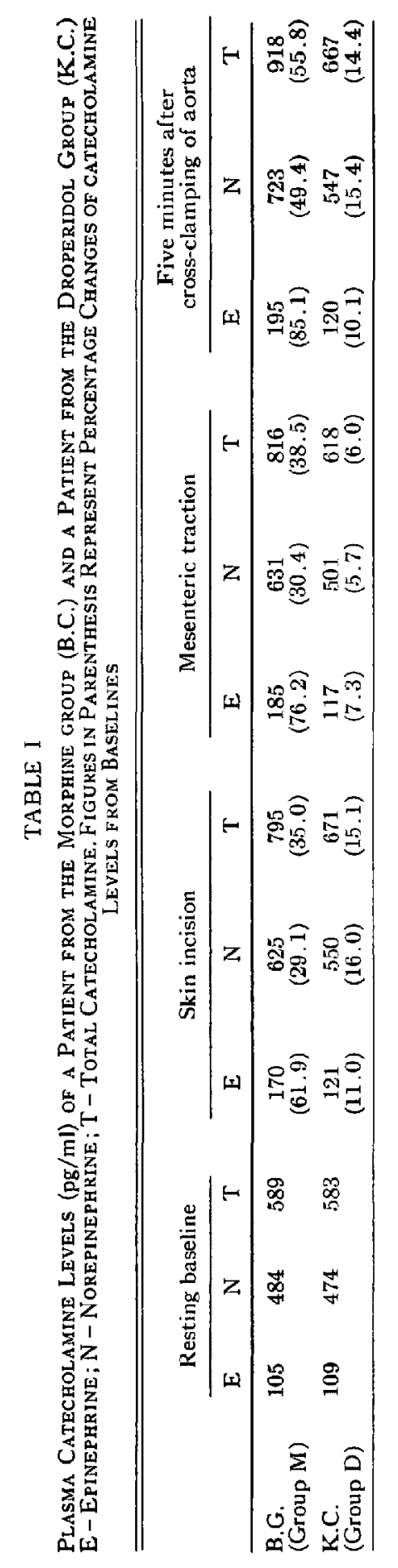


W.T.
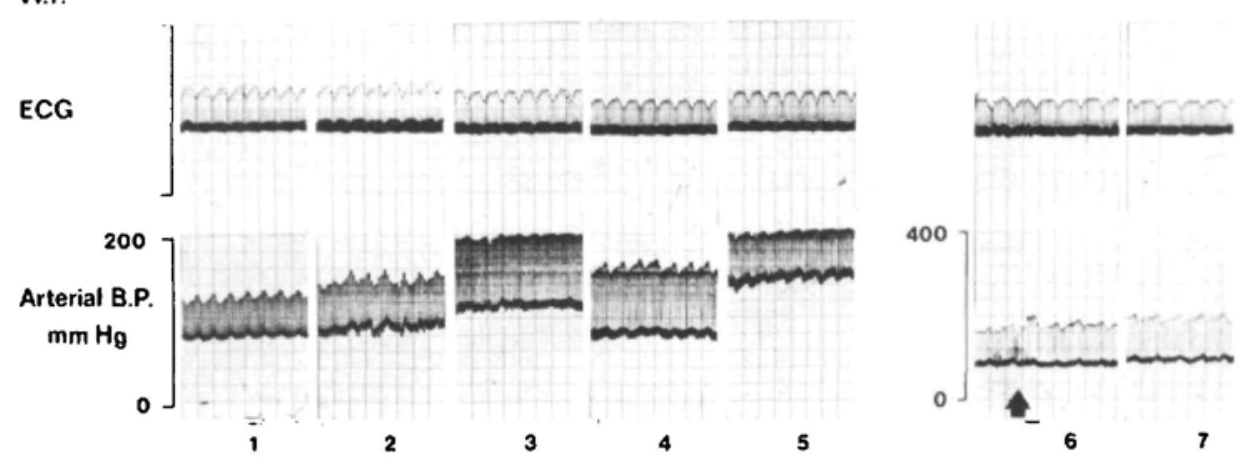

W.T.
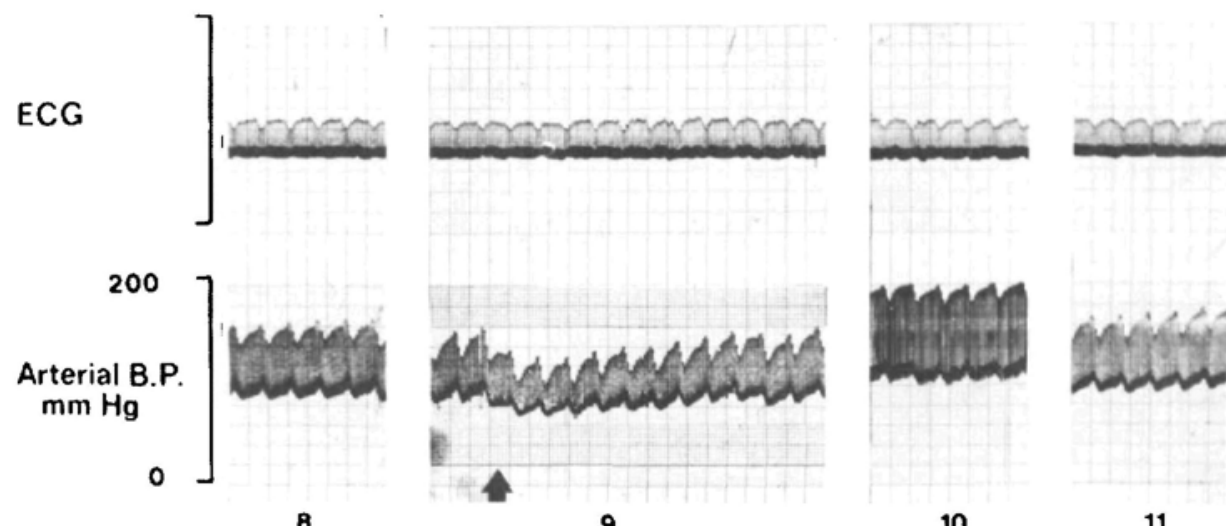

10

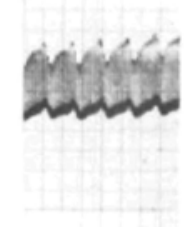

11

Ficure 5. Actual tracings of electrocardiogram and arterial blood pressure of a patient from the morphine group (W.T.) during operation on the lower abdominal aorta. (1) - baseline after induction, (2) - abdominal skin incision, (3) - mesenteric traction, (4) - relaxation of mescnteric traction, (5) - dissection around abdominal aortic aneurysm, (6) - cross-clamping of the aorta, ( 7 - five minutes after clamping of the aorta, $(8)-45$ minutes after clamping of the aorta, (9) - declamping of the aorta, (10) and (11) -5 and 15 minutes after declamping of the aorta respectively.

rise of systolic and diastolic blood pressure from the baseline in the morphine group is associated with mesenteric traction and subsequent manoeuvres. Significant but smaller increases in systolic and diastolic blood pressures occurred in the droperidol group.

Figure 4 also shows that there is no significant change in blood pressure and heart rate when the readings at the time of mesenteric traction, femoral or iliac arterial manipulation and aortic manipulation are compared with those at crossclamping of the aorta. This applies to both the morphine and droperidol groups.

In both groups of patients a transient decrease in systolic and diastolic blood pressure occurred upon declamping of the aorta as shown in Figure 4. 
Plasma catecholamine levels in one patient from the morphine group and one patient from the droperidol group are shown in Table I. The resting total catecholamine level in patient B.G. (group M) was $589 \mathrm{pg} / \mathrm{ml}$, and in patient K.C. (group D) it was $583 \mathrm{pg} / \mathrm{ml}$. During skin incision, there was a greater rise of total catecholamine from resting level in patient B.G. than in patient K.C. (35.0 per cent rise as compared to 15.1 per cent). During mesenteric traction, the increase in total catecholamine from resting level in patient B.G. remained at 38.5 per cent, whereas in patient K.C. it was 6.0 per cent. Five minutes after cross-clamping of the aorta, there was a further rise in total catecholamine levels in both patients, with B.G. having 55.8 per cent of resting level, but K.C. only 14.4 per cent.

Figure 5 is an actual tracing of a patient from the morphine group and Figure 6 is a tracing of a patient from the droperidol group. Comparison of these two tracings reveals that the systolic blood pressure changes are less pronounced in the patient from the droperidol group than the patient from the morphine group.
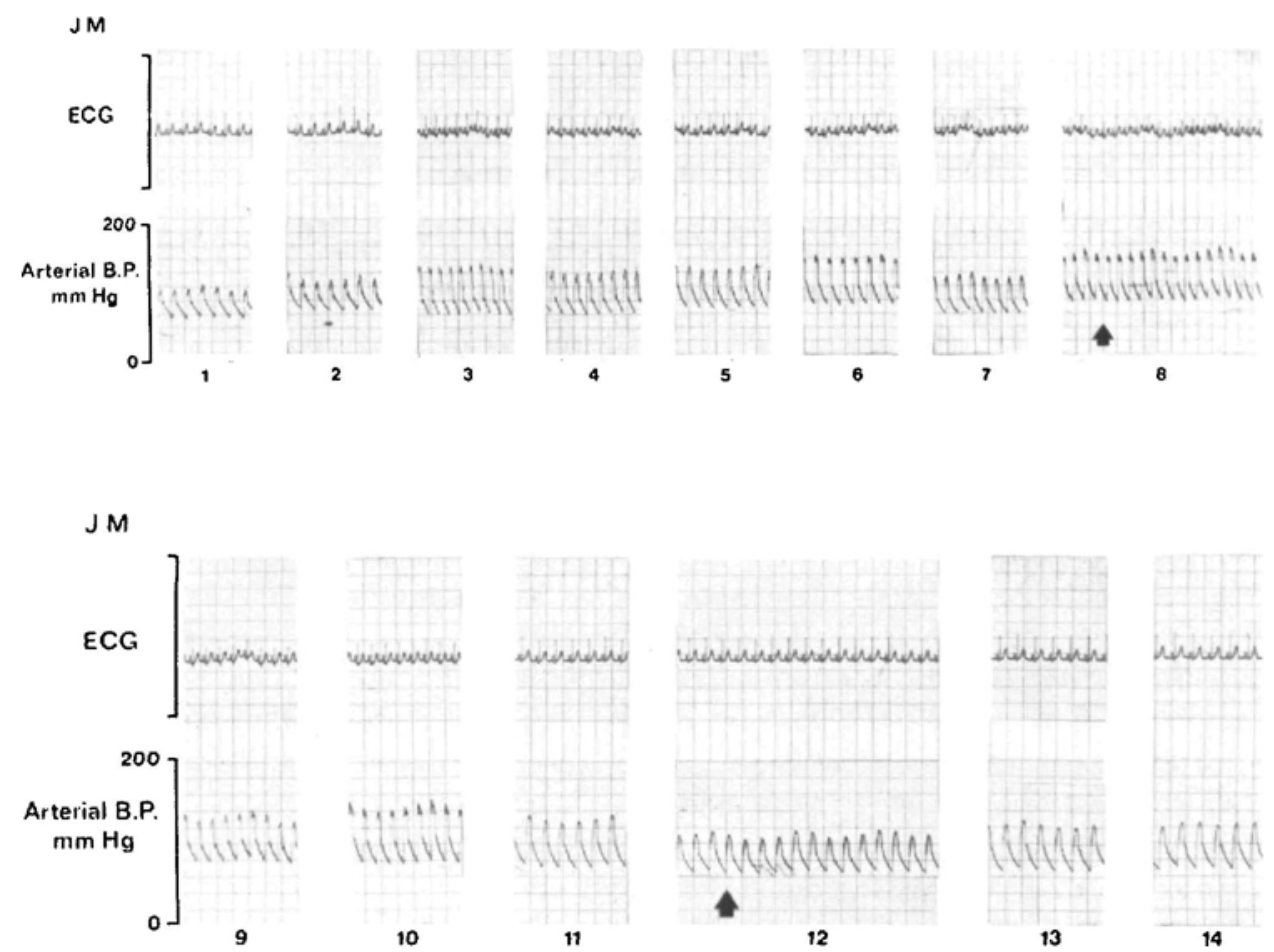

Ficure 6. Actual tracings of electrocardiogram and arterial blood pressure of a patient from the droperidol group (J.M.) during operation on the lower abdominal aorta. (1) - baseline after induction, (2) - abdominal skin incision, (3) - groin skin incision, (4) - groin dissection, (5) - passage of tapes through tunnels in the groins, (6) - mesenterie traction, (7) - relaxation of mesenteric traction, (8) cross-clamping of the aorta, (9), (10), and (11) $-5,15$, and 45 minutes after clamping of the aorta respectively, (12) - declamping of the aorta, (13) and (14) -5 and 15 minutes after declamping of the aorta respectively. 


\section{Discussion}

Statistically significant $(p<0.050-<0.001)$ increases in both systolic and diastolic blood pressure occurred in the morphine group before cross-clamping of the aorta; that is, during traction on the mesentery, manipulation of or dissection around the iliac or femoral arteries and the aorta. When the systolic and diastolic blood pressures at cross-clamping of the aorta were compared with the blood pressures taken during these manoeuvres, there was no significant difference $(p<$ $0.100->0.500)$. This confirms our observation that elevation of systemic blood pressure occurs before cross-clamping. It follows, therefore, that mechanical obstruction to the blood flow within the aorta is not the sole mechanism in the production of this systemic hypertension.

The fact that there was no significant change in the blood pressure from the baselines at skin incision in either group of patients would suggest that they were adequately anaesthetized as determined by conventional clinical methods.

Although statistically significant elevation of blood pressure from the baseline before cross-clamping of the aorta also occurred in the droperidol group, the degree of change was much less than in the morphine group. It appears, therefore, that droperidol modifies blood pressure changes associated with manipulation of the aforementioned structures before cross-clamping of the aorta. In addition, blood pressure elevation upon cross-clamping is significantly less in Group D than in Group $M(p<0.001)$. Elevation of systolic blood pressure upon cross-clamping in Group D was 27.3 torr ( $3.6 \mathrm{kPa}$ ) or 27.3 per cent of baseline as compared with 83.5 torr ( $11 \mathrm{kPa}$ ) or 66.4 per cent of baseline in Group M. Similarly, elevation of diastolic blood pressure at the same time was 8.3 torr $(1 \mathrm{kPa}$ ) or 13.6 per cent of baseline in Group D, as compared to 30.1 torr ( $4 \mathrm{kPa}$ ) or 41.1 per cent of baseline in Group $M$.

The largest change in heart rate in Group $M$ was 13 beats/minute and was associated with aortic manipulation (Figure 4). The largest change in heart rate in Group D was 14 beats/minute and was associated with manipulation of and crossclamping of the aorta. In the absence of cardiac output and detailed catecholamine studies, no conclusions can be drawn from these results.

Abbott, et al. ${ }^{2}$ demonstrated in animal studies that there was a decrease in total renal blood flow associated with infra-renal aortic occlusion, and that the decrease occurred in the renal cortical region. They also demonstrated that this cortical ischaemic pattern persisted for at least one hour after re-establishment of aortic flow. Administration of mannitol through the renal artery was shown to improve cortical flow fraction. ${ }^{3}$ Similar data is lacking in man.

In our study, urinary output was adequate in the two groups of patients, without the use of mannitol or diuretics, although the urinary output in Croup D appeared to be greater than in Group M (Table II). The decreased urinary output frequently associated with operations on the lower aorta is at least partially due to hypovolaemia due to loss of fluid to the third space, secondary to intra-abdominal manipulation of the bowel.

The increases of epinephrine and norepinephrine from basal levels were generally higher in the patient from the morphine group (B.G.) than the one from the 
TABLE II

URINARY OUTPUT (ML/KG/HOUR) DURING Cross-Clamping of THE AORTA

\begin{tabular}{cc}
\hline \hline Group M & Group D \\
\hline 1.01 & 1.10 \\
0.71 & 1.0 \\
0.91 & 2.12 \\
1.17 & 0.95 \\
0.73 & 4.3 \\
0.66 & 1.25 \\
1.32 & \\
Mean 0.93 & Mean 1.79 \\
\hline
\end{tabular}

droperidol group (K.C.) (Table I). The maximal increase of 55.8 per cent in the total catecholamine levels in patient B.G. occured five minutes after cross-clamping of the aorta. At this point, the elevation of the total catecholamine in patient K.C. was only 14.4 per cent. While it is known that catecholamine release occurs with the use of morphine, ${ }^{4,5}$ it is unlikely that morphine was the main cause of increased levels of catecholamines since the patients in the droperidol group also received the same dose of morphine per unit of body weight before the addition of droperidol. It must be emphasized that only one patient from each group was investigated. If this were a consistent finding, it could be suggested that haemodynamic changes associated with abdominal aortic operations may be related to catecholamine release, and that droperidol modifies the release of catecholamines.

Other mechanisms may be responsible for hypertensive changes during lower aortic surgery. During manipulation of the mesentery or of a major artery, the renal blood flow may decrease either through neurogenic reflex pathways or secondary to the release of catecholamines. The decrease in renal blood flow may cause renal cortical ischaemia and may result in the release of renin. ${ }^{6}$ Furthermore, catecholamines are known to cause the release of renin. ${ }^{7}$ A possible mechanism for blood pressure elevation in operations on the lower aorta is summarized in Figure 7.

Many theories have been propounded in an attempt to account for the hypotensive changes immediately following declamping of the aorta, the so-called "declamping phenomenon." The "washout" acidosis theory ${ }^{8}$ was not confirmed by other investigators. Perry, ${ }^{0}$ giving adequate volumes of balanced salt solution and blood prior to declamping and with gradual restoration of blood flow to distal extremities by gradual release of the aortic clamp, was able to prevent significant decreases in blood pressure and cardiac output. Thompson, et al., ${ }^{10}$ using satisfactory blood pressure and adequacy of urinary output as their guide for fluid replacement and without the routine use of mannitol, achieved improvement in the mortality rate and maintenance of renal function in aortic operations in their series. In both groups of our patients, using central venous pressure, systemic blood pressure and urinary output as our guides for fluid replacement, the decrease in blood pressure was only transient and it returned to pre-clamp levels within five minutes. 


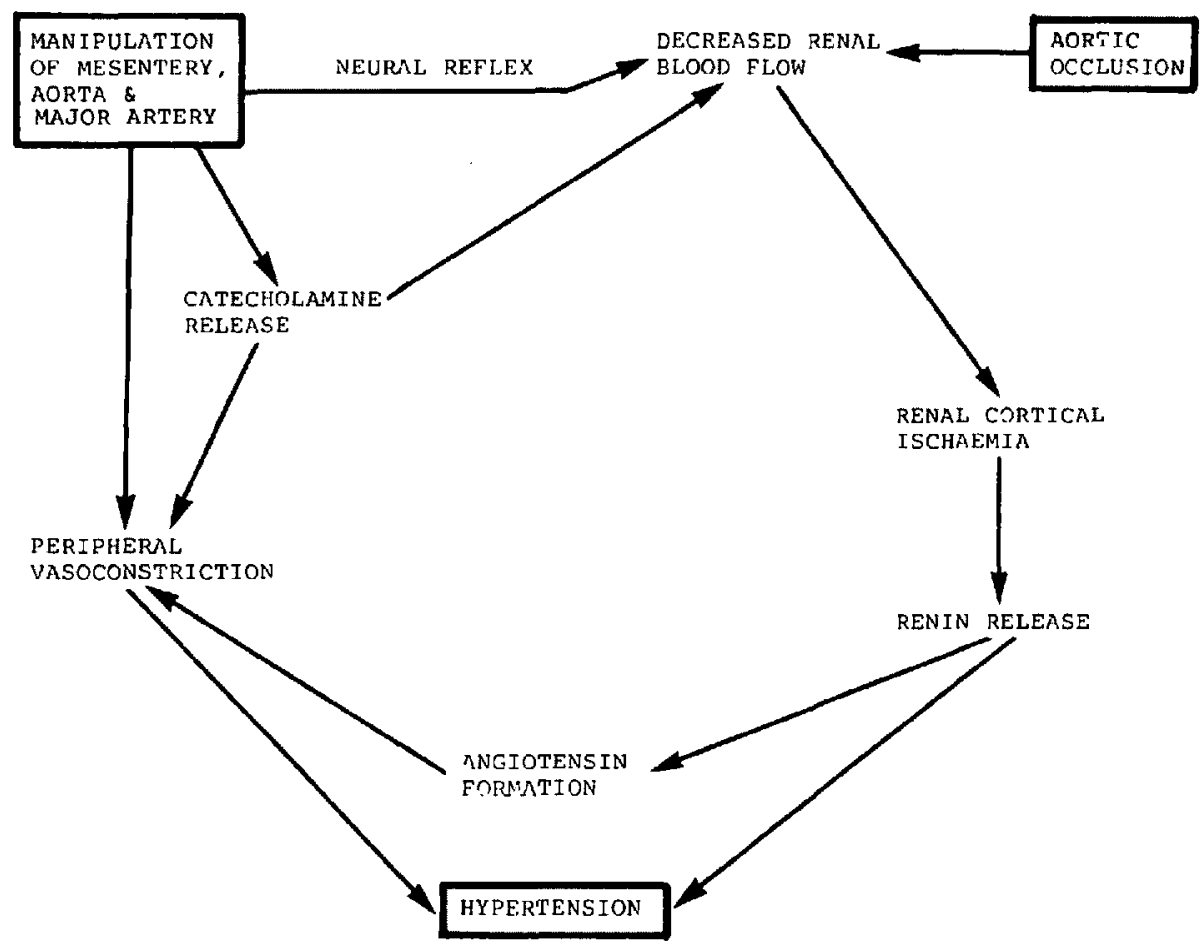

Ficune 7. Possible mechanism of hypertension in operations on the lower abdominal aorta.

Since morphine in high doses causes decreased systemic vascular resistance and increased capacitance, ${ }^{11}$ and droperidol has known alpha blocking properties, ${ }^{12}$ the use of either or both of these agents in a dehydrated patient will result in hypotension. It is for these reasons that adequate hydration was assured in our patients before operation and that the drugs were administered in divided doses with close monitoring of arterial blood pressure, heart rate, and central venous pressure.

\section{SUMMARY}

Hypertensive responses during operations on the abdominal aorta are common. We have shown that hypertensive changes occur before cross-clamping of the aorta. We have also shown that droperidol modifies the hypertensive changes in operations on the lower aorta. Although further studies are required, our preliminary results show a higher rise of serum epinephrine and norepinephrine levels in one patient receiving morphine, as compared to one patient receiving the same dose per unit body weight of morphine plus droperidol. With maintenance of adequate pre-operative hydration and intra-operative fluid and blood replacement, declamping hypotension was transient in both groups of our patients.

\section{RÉSUMÉ}

De dangereuses variations de la pression artérielle sont d'observation courante en chirurgie aortique. 
Notre impression clinique était que des hypertensions significatives survenaient avant le clampage aortique et que ces réactions pouvaient être atténués par l'usage de Dropéridol.

Dans le but de confirmer ou d'infirmer nos impressions, nous avons étudié quinze malades soumis à une chirurgie aortique au-dessous du niveau des rénales. Ces quinze malades ont été divisés en deux groupes. Les malades du premier groupe ont reçu une anesthésie à la Morphine $(1 \mathrm{mg} / \mathrm{kilo})$ et ceux du second groupe une anesthésie avec des doses semblables de Morphine associée au Dropéridol.

Les résultats ont confirmé nos impressions cliniques.

De plus, un remplacement attentif des pertes sanguines et des liquides a permis d'obtenir des diurèses satisfaisantes sans avoir recours au Mannitol et à d'autres diurétiques. Les hypotensions observées au déclampage ont été transitoires.

Le taux de catécholamine étudié chez un malade anesthésié à la Morphine a été supérieur au taux observé chez un malade anesthésié à la MorphineDropéridol.

\section{REFERENCES}

1. The Interhospital Cardiovascular Surgery Group of the University of Toronto, \& Aareur, F.M., Gunstensen, J., Jain, K., Polllu, N., Spratt, E.H., \& Tutassaura, H. Surgical treatment of abdominal aortic aneurysms in Toronto: a study of 1,013 patients. Can. Med. Assoc. J. 107: 1091 ( 1972).

2. Anнotт, W.H., CoOper, J.D., \& Austen, W.G. The effect of aortic clamping and declamping on renal blood flow distribution. J. Surg. Research 14:385-392 (1973).

3. Aввотт, W.M. \& Austen, W.G. The reversal of renal cortical ischemia during artic occlusion by mannitol. J. Surg. Research 16: 482-489 (1974).

4. VASKo, J.S., HaNney, R.P., BHAWLEY, R.K., et al. Effects of morphine on ventricular function and myocardial contractile force. Am. J. Physiol, 210:329-334 (1966).

5. Stanlex, T.H., Isern-Amaral, J., \& Lathrop, G.D. Urine norepinephrine excretion in patients undergoing mitral or aortic valve replacement with morphine anaesthesia. Anaesthesia \& Analgesia. Cumrent Researches 54: 4: 509 (1975).

6. GaL, T.J., Cooperman, L.H., \& Berkowirz, H.D. Plasma renin activity in patients undergoing surgery of the abdominal aorta, Ann. Surg. 179: 65 (1974).

7. JohNson, J.A., DAvis, J.O., \& WITTY, R.T. Effects of catecholamines and renal nerve stimulation on renin release in the non-filtering kidney. Circulation Res. 29: 646-653 (1971).

8. Mansherga, A.R., Cox, E.F., Flotte, C.T., \& Buxton, R.W. "Washout" acidosis following resection of aortic aneurysms. Ann. Surg. 163: 5: 778 (1966).

9. PERHY, H.O. Haemodynamics of temporary abdominal aortic occlusion. Ann. Surg. I68: $193-200(1968)$

10. Thompson, J.E., Vodman, R.W., Austin, D.J., \& Kartchiner, M.M. Prevention of hypotensive and renal complications of aortic surgery using balanced salt solution. Ann. Surg. I67: 767 (1968).

11. Lowenstein, E., Hallowell, P., Levine, F.H., Dagcett, W.M., Austex, G., \& Laver, M.B. Cardiovascular response to large doses of intravenous morphine in man. N.E.J.M. 281: 25: 1389 (1969).

12. WhitaAn, J.G. \& Russell, W.J. The acute cardiovascular changes and adrenergic blockade by droperidol in man. Brit. J. Anaesth. 43: 581 (1971). 